\title{
BJR: Searching for a characteristic identity
}

For the group of researchers that founded the SBPJor in 2003 and created Brazilian Journalism Research in 2004, there was an excessive emphasis in communication research on schematic theoretical models, influenced by other more consolidated scientific areas such as semiotics, linguistics and sociology. But their conceptual models were not always adapted to the knowledge of the profession and to the study of the relations of journalism with society.

These spurious models have little capability for explaining the profession's reality and the role of journalism in contemporary life. Consequently, journalism research moved away from the professional field and placed researchers on one side and journalists on the other, distant and mistrustful. This situation worried the researchers. The main objective of the society and of the magazine was to create a characteristic forum and stimulate research on a theory of the news which discussed the impasses of the profession and the identity of journalism in a period of accelerated mutations.

The first issue was published in the first semester of 2005. From then on the magazine came out regularly and in the first semester of 2007 it also appeared in an electronic version on the Internet, with free access. After three years of existence, the magazine today has a regular semiannual periodicity, a dynamic editorial management befitting an international academic magazine and a directed circulation. The circulation is 700 copies, distributed free of charge to the 300 members of the SBPJor and sent to the main university libraries in Brazil and in the world through an exchange system. 


\section{|BJR: Original scientific contribution}

In only three years the BJR has consolidated its identity, has become a meeting point for the community, has maintained a regular periodicity, has continued with the evaluation by peers of the articles spontaneously sent in for publication and has become available on the Internet. The BJR has already made an original contribution to the advance of the scientific discipline of journalism, although it should continually correct its editorial and academic courses in the future. BJR is consolidating all the requirements to become shortly a magazine for international reference achieving all the levels of graphic and editorial quality required by the agencies., 